\title{
High tin intake reduces copper status in rats through inhibition of copper absorption
}

\author{
BY SHIGUANG YU ${ }^{1,2}$ AND ANTON C. BEYNEN ${ }^{1,2 *}$ \\ ${ }^{1}$ Department of Human Nutrition, Wageningen Agricultural University, PO Box 8129 . \\ 6700 EV Wageningen, The Netherlands \\ ${ }^{2}$ Department of Large Animal Medicine and Nutrition, Faculty of Veterinary Medicine, \\ Utrecht University, PO Box 80.157, 3508 TD Utrecht, The Netherlands
}

(Received 26 July 1993 - Revised 7 February 1994-Accepted 18 October 1994)

\begin{abstract}
The mechanism underlying the reduced $\mathrm{Cu}$ status in rats fed on a high-Sn diet was investigated. Male rats aged 4 weeks were fed ad lib. on purified diets containing either 1 or $100 \mathrm{mg} \mathrm{Sn} / \mathrm{kg}$ and demineralized water for a period of 4 weeks. The high-Sn diet had no effect on feed intake, body-weight gain or weight of liver and kidney but significantly reduced $\mathrm{Cu}$ concentrations in plasma, liver and kidney. Biliary $\mathrm{Cu}$ excretion was decreased significantly in rats fed on the high-Sn diet. Apparent $\mathrm{Cu}$ absorption ( $\mathrm{Cu}$ intake - faecal $\mathrm{Cu}$ ) was not affected by the high-Sn diet, but the estimate of true $\mathrm{Cu}$ absorption (Cu intake - (faecal $\mathrm{Cu}$ - biliary $\mathrm{Cu}$ )) was significantly reduced. We conclude that high $\mathrm{Sn}$ intake reduces $\mathrm{Cu}$ status in rats through inhibition of $\mathrm{Cu}$ absorption. The decreased biliary $\mathrm{Cu}$ excretion observed on the high-Sn diet is a result of the reduced $\mathrm{Cu}$ absorption.
\end{abstract}

Tin: Copper : Biliary excretion: Metabolism: Rat

In rats, high intakes of $\mathrm{Sn}$ have been shown to reduce the concentration of $\mathrm{Cu}$ in plasma, liver and kidney (Greger \& Johnson, 1981; Pekelharing et al. 1994) but the mechanisms involved are unknown. Biliary $\mathrm{Cu}$ is poorly absorbed (Owen, 1964; Farrer \& Mistilis, 1967) and $\mathrm{Cu}$ excretion in urine is low (Van den Berg \& Beynen, 1992) so that the main mechanism of $\mathrm{Cu}$ excretion is via the bile (Cartwright \& Wintrobe, 1964). We decided to test which of two mechanisms may be involved in rats fed on a high-Sn diet. The first is that a high intake of $\mathrm{Sn}$ inhibits intestinal $\mathrm{Cu}$ absorption which would lead to reduced excretion of copper in bile to achieve $\mathrm{Cu}$ balance; alternatively, high $\mathrm{Sn}$ intake stimulates biliary $\mathrm{Cu}$ excretion which would lead to enhanced $\mathrm{Cu}$ absorption. Either mechanism could explain the impairment of $\mathrm{Cu}$ status by high intakes of $\mathrm{Sn}$.

MATERIALS AND METHODS

The protocol of the experiment was approved and its conduct supervised by the animal welfare officer of Wageningen Agricultural University.

Animals and diets

Male Wistar rats (Hsd/Cpb:WU; Harlan/CPB, Zeist, The Netherlands), aged about 4 weeks, were used. On arrival they were housed in groups of five in stainless steel cages $(600 \times 210 \times 190 \mathrm{~mm})$ with wire mesh bases and given ad lib. a commercial, pelleted diet

* For reprints. 
(RMH-B; Hope Farms, Woerden, The Netherlands) and tap water. After $3 \mathrm{~d}$ the semipurified control diet (Table 1) and demineralized water were given. The control diet was formulated according to the recommended nutrient requirements of rats (National Research Council, 1978). After $4 \mathrm{~d}$ (day -4) the rats were divided randomly into two groups of twelve each and stratified for body weight. After another $4 \mathrm{~d}$ (day 0 ) one group was randomly allocated to the semi-purified, high-Sn diet containing $100 \mathrm{mg}$ added $\mathrm{Sn} / \mathrm{kg}$ (Table 1), and the other group remained on the control diet. Extra Sn was added to the test diet in the form of $\mathrm{SnCl}_{2}$. The control and test diets were balanced for $\mathrm{Ca}$ and $\mathrm{Cl}$ (Table 1). Both groups had free access to the diets, which were in powdered form, and to demineralized water. Feed intake and body weight were recorded regularly. From day -4 the rats were housed individually in metabolism cages $\left(31400 \mathrm{~mm}^{2} \times 120 \mathrm{~mm}\right)$ in a room with controlled lighting (light on: 06.00-18.00 hours), temperature (19-21 ${ }^{\circ}$ ) and relative humidity $(50-60 \%)$.

\section{Collection of samples}

Faeces and urine were collected separately and quantitatively during days -4 to 0,0 to 4 , 7 to 11 and 24 to 28 . At the end of the experiment (day 28), bile was collected by common bile duct cannulation with polyethylene tubing (i.d. $0.28 \mathrm{~mm}$, o.d. $0.61 \mathrm{~mm}$, Intramedic, Clay Adams, Parsippary, NJ, USA). The abdomen was opened while the rats were under anaesthesia induced by a combination of ketamine $(60 \mathrm{mg} / \mathrm{kg}$ body weight) administered intramuscularly, and xylazine $(8 \mathrm{mg} / \mathrm{kg}$ body weight) administered subcutaneously. This combination of the two drugs was used because it has been shown not to influence bile flow in rats (Fleck \& Barth, 1990). After the cannula was inserted into the common bile duct and secured with suture thread the rats were kept on a heating pad (36-38 $)$. Bile was collected into pre-weighed vials for $1 \mathrm{~h}$ and the volume of bile was calculated from the weight and the determined specific gravity of the bile. One rat in the control group died immediately after induction of anaesthesia. Following bile collection, blood samples were taken from the anaesthetized rats by abdominal aorta puncture into heparinized tubes. The rats were then killed and liver and left kidney were removed and weighed. All samples collected were stored at $-20^{\circ}$ until analysis.

\section{Analytical methods}

The concentrations of $\mathrm{Cu}$ in organs, faeces, urine and feed samples were determined by flame atomic absorption spectrometry (Perkin-Elmer 2380; Perkin-Elmer Corporation, Norwalk, CT, USA). For the determination of $\mathrm{Cu}$ in organs, samples were dried in a vacuum dryer for $48 \mathrm{~h}$ and digested in $1.0 \mathrm{ml} 14 \mathrm{M}-\mathrm{HNO}_{3}$ at $80^{\circ}$ for $2 \mathrm{~h}$. Samples of faeces, but not feed samples, were also dried in the vacuum dryer before ashing. Samples of feed and dried faeces were ashed at $500^{\circ}$ for $17 \mathrm{~h}$ in a muffle furnace and then dissolved in $6 \mathrm{M}$ $\mathrm{HCl}$. The determination of $\mathrm{Cu}$ in bile and plasma was carried out using flameless atomic absorption spectrometry (Varian AA-300; Varian Techtron Pty Ltd, Springvale, Victoria, Australia) after proper dilution of the samples with demineralized water. An external control in the form of a bovine liver sample (NBS 1577b; National Institute of Standards and Technology, Gaithersburg, MD, USA) was used to assess bias of $\mathrm{Cu}$ analysis. Analysed $\mathrm{Cu}$ concentration was $103 \cdot 8 \%$ (SE $1 \cdot 73, n 4$ ) of the NBS certified value.

\section{Statistical analyses}

The data of the control and test groups were subjected to Student's $t$ test to identify statistically significant differences. The Mann-Whitney $\mathrm{U}$ test was used to evaluate $\mathrm{Cu}$ 
Table 1. Composition of the experimental diets

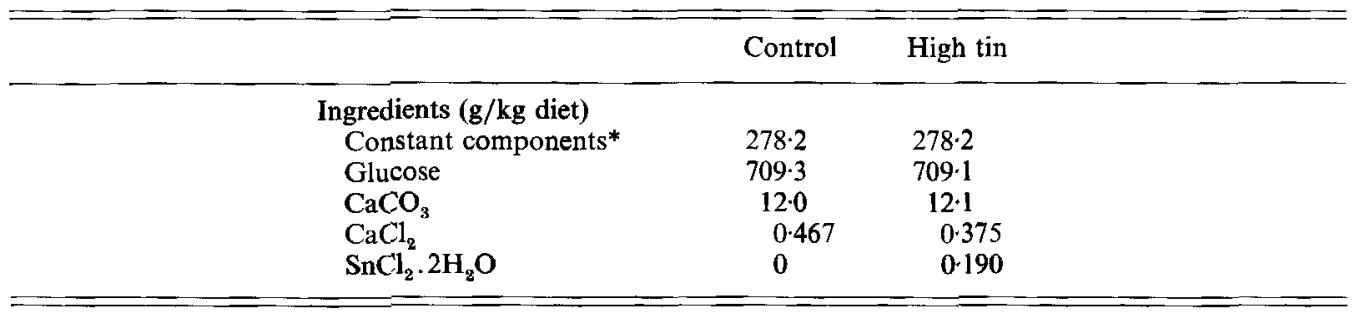

* The constant components consisted of $(\mathrm{g} / \mathrm{kg}$ diet $)$ : casein 151 , maize oil 25 , coconut fat 25 , cellulose 30 , $\mathrm{NaH}_{2} \mathrm{PO}_{4} \cdot 2 \mathrm{H}_{2} \mathrm{O} 15 \cdot 1, \mathrm{MgCO}_{3} 1 \cdot 4, \mathrm{KCl} \mathrm{1} \cdot 0, \mathrm{KHCO}_{3} 7 \cdot 7$, mineral premix 10 and vitamin premix 12 . The mineral premix consisted of (mg/kg diet): $\mathrm{FeSO}_{4} .7 \mathrm{H}_{2} \mathrm{O} 174, \mathrm{MnO}_{2} 79, \mathrm{ZnSO}_{4} . \mathrm{H}_{2} \mathrm{O} 33, \mathrm{NiSO}_{4} .6 \mathrm{H}_{2} \mathrm{O} 13, \mathrm{NaF} 2, \mathrm{KI} \mathrm{0-2}$, $\mathrm{CuSO}_{4} .5 \mathrm{H}_{2} \mathrm{O} 15 \cdot 7, \mathrm{Na}_{2} \mathrm{SeO}_{3} .5 \mathrm{H}_{2} \mathrm{O} 0 \cdot 3, \mathrm{CrCl}_{3} .6 \mathrm{H}_{2} \mathrm{O} 1 \cdot 5, \mathrm{SnCl}_{2} .2 \mathrm{H}_{2} \mathrm{O} 1 \cdot 9, \mathrm{NH}_{4} \mathrm{VO}_{3} 0 \cdot 2$ and maize meal $9679 \cdot 2$. The vitamin premix consisted of $(\mathrm{mg} / \mathrm{kg}$ diet $):$ thiamin 4 , riboflavin 3 , nicotinamide 20 , D, L-calcium pantothenate 17.8 , pyridoxine 6 , cyanocobalamin $50(0.1 \%$ purity), choline chloride 2000 , pteroylglutamic acid 1 , biotin 2 , menadione $0.05, D, L-\alpha$ tocopheryl acetate 60 , retinyl acetate and retinyl palmitate 8 (1200 retinol equivalents), cholecalciferol $0 \cdot 025$, maize meal $9828 \cdot 125$.

concentrations in liver and plasma because the variances were not homogeneous ( $F$ test). $\mathrm{Cu}$ absorption and urinary $\mathrm{Cu}$ excretion were evaluated using the multivariate ANOVA repeated measurements test. The level of significance was pre-set at $P<0.05$. All data were processed using a computer program (SPSS Inc., 1988).

\section{RESULTS}

Feed consumption, body and organ weights

The high-Sn diet had no effect on feed consumption and body weight of the rats (Table 2). Likewise, there was no effect of $\mathrm{Sn}$ on the weights of liver and kidney.

\section{Indicators of copper status}

Fig. 1 shows the $\mathrm{Cu}$ concentrations in selected organs and plasma. The high-Sn diet resulted in significantly reduced $\mathrm{Cu}$ concentrations in plasma, liver and kidney.

\section{Apparent copper absorption}

Analysed $\mathrm{Cu}$ concentrations of both the control and test diets were found to be $5 \mathrm{mg} / \mathrm{kg}$. Apparent $\mathrm{Cu}$ absorption was calculated as $\mathrm{Cu}$ intake minus faecal $\mathrm{Cu}$ excretion. During the course of the experiment absolute $\mathrm{Cu}$ absorption increased in both groups (Fig. 2) because feed intake increased (Table 2) but the high-Sn diet did not affect apparent $\mathrm{Cu}$ absorption (Fig. 2). Apparent $\mathrm{Cu}$ absorption expressed as a percentage of $\mathrm{Cu}$ intake dropped with time (results not shown). The high-Sn diet systematically lowered group means of urinary $\mathrm{Cu}$ excretion (Fig. 2), but the effect failed to reach statistical significance $(P=0 \cdot 118)$.

\section{Biliary copper excretion}

Bile flow and biliary $\mathrm{Cu}$ excretion are illustrated in Fig. 3. The high-Sn diet had no effect on bile flow, but significantly reduced the absolute amount of $\mathrm{Cu}$ excreted in bile. 
Table 2. Feed intake and body and organ weights of rats fed on a control diet or a high-tin diet*

(Mean values with their standard errors for twelve rats per dietary group)

\begin{tabular}{|c|c|c|c|c|c|}
\hline & \multirow[t]{2}{*}{ Diet... } & \multicolumn{2}{|c|}{ Control } & \multicolumn{2}{|c|}{ High tin } \\
\hline & & Mean & $\mathrm{SE}$ & Mean & SE \\
\hline \multicolumn{6}{|c|}{ Body weight (g) } \\
\hline Initial & & $95 \cdot 8$ & $2 \cdot 91$ & $94 \cdot 6$ & $2 \cdot 11$ \\
\hline Final & & $266 \cdot 2$ & $9 \cdot 13$ & $269 \cdot 4$ & $6 \cdot 25$ \\
\hline \multicolumn{6}{|c|}{ Feed intake $(g / d)$} \\
\hline Days 0-7 & & $12 \cdot 7$ & 0.49 & $12 \cdot 5$ & $0 \cdot 38$ \\
\hline Days $21-28$ & & $21 \cdot 6$ & 0.71 & $21 \cdot 9$ & 0.53 \\
\hline \multicolumn{6}{|c|}{ Organ weight ( $\mathrm{g} / \mathrm{kg}$ body weight) } \\
\hline Liver & & $38 \cdot 7$ & $0 \cdot 76$ & $38 \cdot 6$ & 0.42 \\
\hline Kidney & & $3 \cdot 3$ & 0.08 & $3 \cdot 3$ & 0.05 \\
\hline
\end{tabular}

* For details of diets, see Table 1.
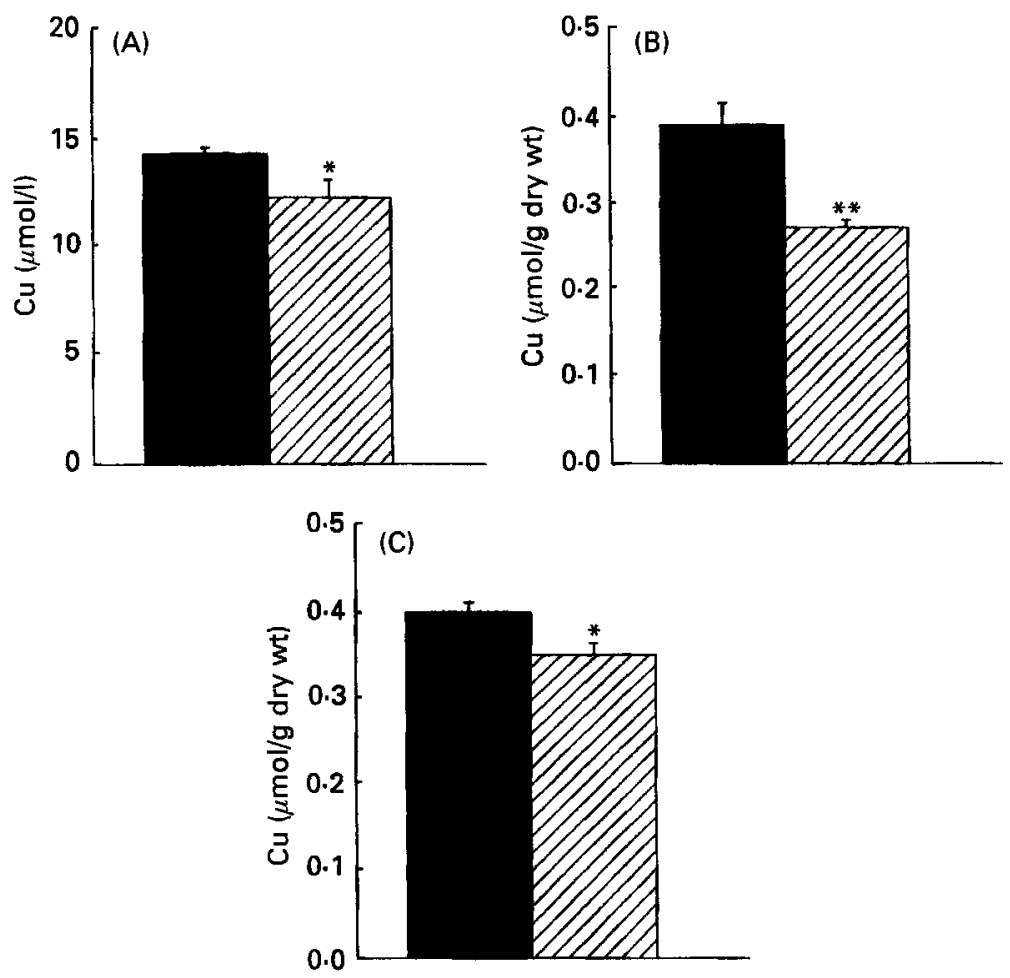

Fig. 1. Copper concentrations in (A) plasma, (B) liver and (C) kidney of rats fed on a control diet ( $\square$ ) or a hightin diet $(\square)$. Values are means with their standard errors for twelve rats $(n 11$ for plasma values of the control group). Mean values were significantly different from those of controls: ${ }^{*} P<0.05, * * P<0.01$. For details of diets and procedures, see Table 1 and pp. 863-865 

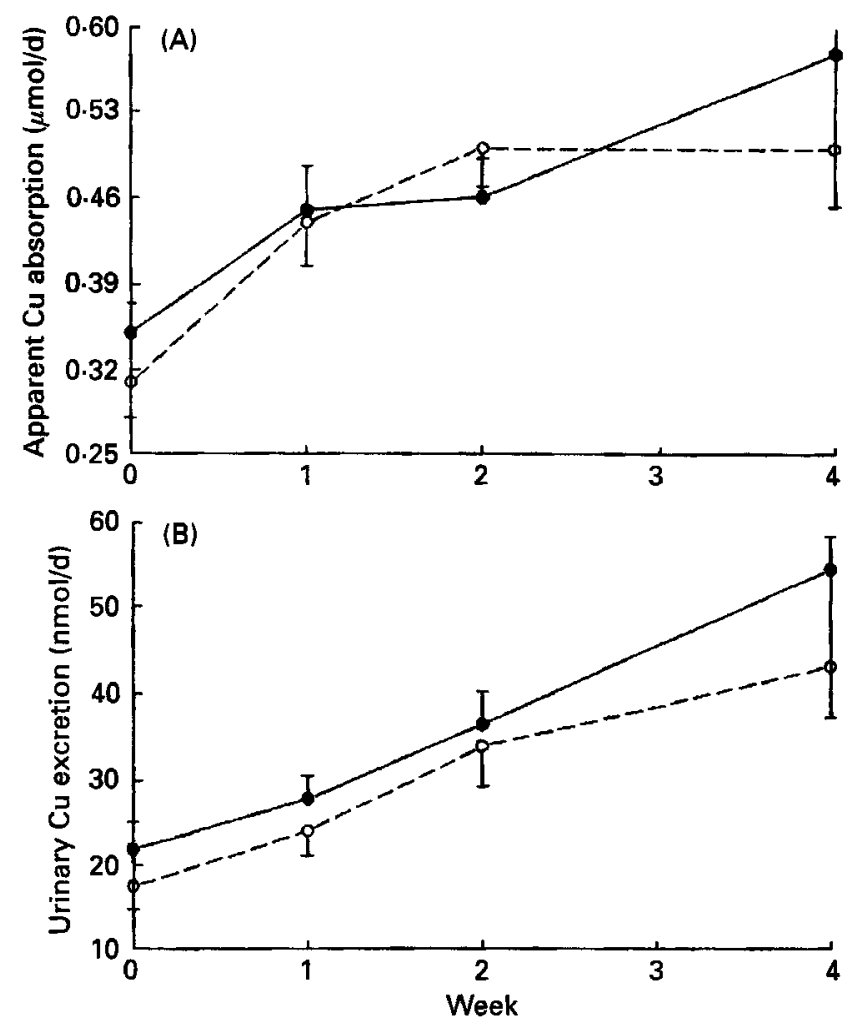

Fig. 2. Time course of (A) apparent copper absorption and (B) urinary copper excretion of rats fed on a control diet $(-)$ ) or a high-tin diet $\left(\mathrm{O}_{--}-\mathrm{O}\right)$. Values are means for twelve rats, with their standard errors indicated by vertical bars. The high-tin diet did not significantly influence apparent copper absorption or urinary copper excretion. For details of diets and procedures, see Table 1 and pp. 863-865.
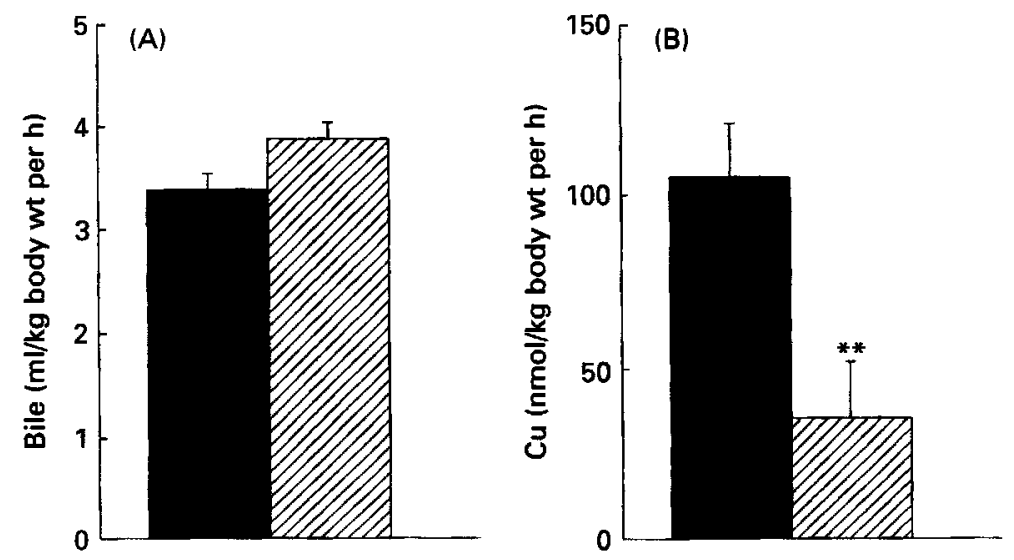

Fig. 3. (A) Bile flow and (B) biliary excretion of copper in rats fed on a control diet ( $\square$ ) or a high-tin diet ( $\square$ ) for $28 \mathrm{~d}$. Values are means for eleven (control) or twelve (high-tin) rats, with their standard errors indicated by vertical bars. ** Mean value was significantly different from that of the control, $P<0 \cdot 01$. For details of diets and procedures, see Table 1 and pp. 863-865. 


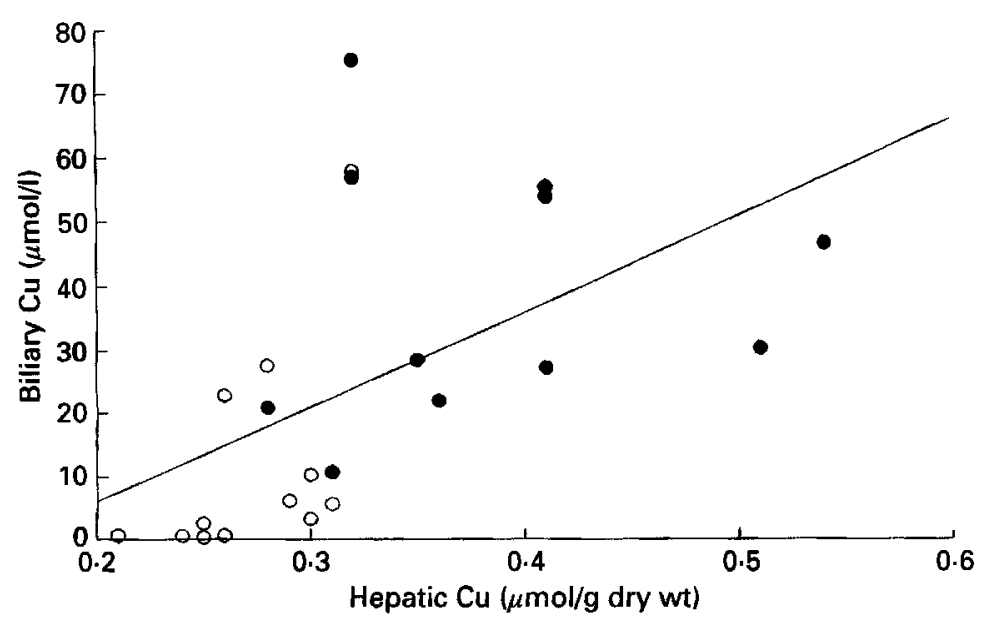

Fig. 4. Relationship between biliary copper concentration and hepatic copper concentration in individual rats fed on either a control diet $(\bigcirc)$ or a high-tin $\operatorname{diet}(O)$ for $28 \mathrm{~d}$. The regression equation is $y=150 x-24(r 0.54, n 23$, $P<0.01$ ).

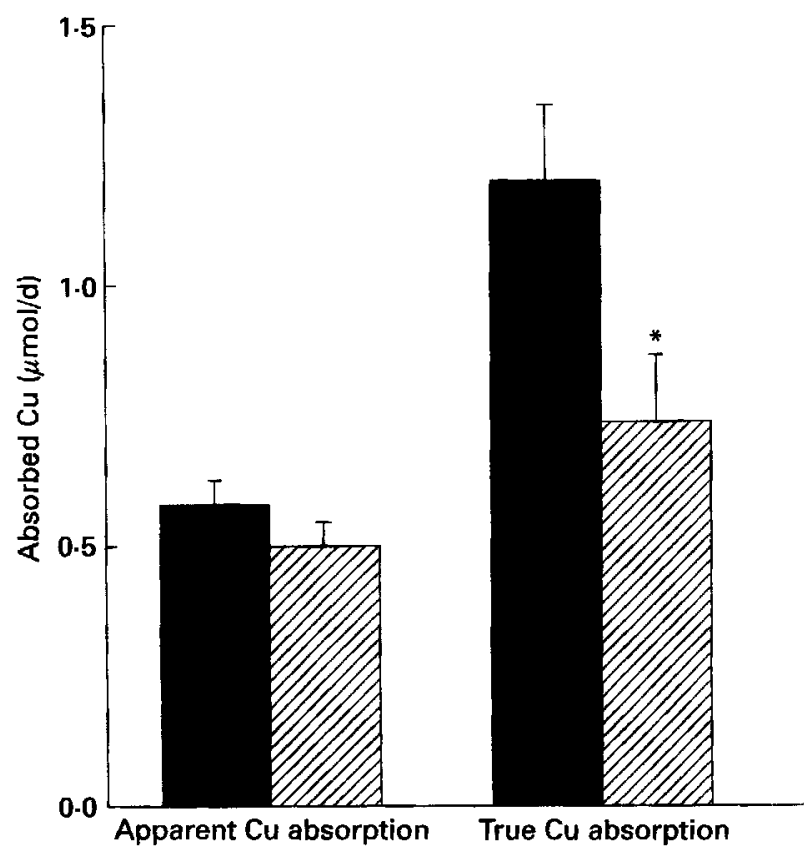

Fig. 5. Apparent and true copper absorption rates in rats fed on a control diet ( $\boldsymbol{\square}$ ) or a high-tin diet (因) for 28 d. Apparent copper absorption was calculated as copper intake-faecal copper, and true copper absorption as copper intake - (faecal-biliary copper). Values are means for eleven (control) or twelve (high-tin) rats, with their standard errors indicated by vertical bars. * Mean value was significantly different from that for the controls, $P<0.05$. For details of diets and procedures, see Table 1 and pp. 863-865.

\section{DISCUSSION}

The observed lowering effects of the high-Sn diet on $\mathrm{Cu}$ concentrations in plasma, liver and kidney agree well with previous findings (Greger \& Johnson, 1981 ; Pekelharing et al. 1994). The challenge with $100 \mathrm{mg} \mathrm{Sn} / \mathrm{kg}$ diet did not affect feed consumption and weight gain 
of the rats. Pekelharing $e t$ al. (1994) found that feed intake was significantly reduced in rats fed on a diet containing as much as $200 \mathrm{mg} \mathrm{Sn} / \mathrm{kg}$.

High $\mathrm{Sn}$ intake had no effect on bile flow but significantly reduced the amount of $\mathrm{Cu}$ excreted in bile. Since the concentration of $\mathrm{Cu}$ in bile was significantly related, albeit weakly, to that in liver (Fig. 4), it is likely that biliary $\mathrm{Cu}$ excretion is determined by the concentration of $\mathrm{Cu}$ in the liver. The tendency towards a lower urinary $\mathrm{Cu}$ excretion in the rats fed on the high-Sn diet may also be secondary to the reduced $\mathrm{Cu}$ status.

The reduced $\mathrm{Cu}$ status observed after high $\mathrm{Sn}$ intake could result in reduced $\mathrm{Cu}$ excretion in bile and urine which, in turn, could lead to reduced $\mathrm{Cu}$ absorption. However, apparent $\mathrm{Cu}$ absorption was not systematically influenced by $\mathrm{Sn}$ loading. $\mathrm{Cu}$ is discharged from the body mainly via bile (Cartwright \& Wintrobe, 1964) while biliary $\mathrm{Cu}$ is poorly reabsorbed (Owen, 1964; Farrer \& Mistilis, 1967). The diurnal rate of biliary $\mathrm{Cu}$ excretion is not constant (Dijkstra et al. 1991), but assuming that it is, and that $\mathrm{Cu}$ excreted in bile is not reabsorbed, true $\mathrm{Cu}$ absorption can be calculated as: $\mathrm{Cu}$ intake $-($ faecal $\mathrm{Cu}-$ biliary $\mathrm{Cu})$. In the rats fed on the control and high-Sn diets, biliary $\mathrm{Cu}$ excretion rates (day 28) were 0.62 (SE 0.12 ) and $0.24(\mathrm{SE} 0 \cdot 10) \mu \mathrm{mol} / \mathrm{d}$, and faecal Cu excretion rates (days 24 to 28 ) were 1.12 (SE 0.05) and 1.21 (SE 0.04) $\mu \mathrm{mol} / \mathrm{d}$ respectively. Mean $\mathrm{Cu}$ intake during the period day 24 to day 28 was $1.7 \mu \mathrm{mol} / \mathrm{d}$ for both groups. Thus, unlike apparent $\mathrm{Cu}$ absorption, true $\mathrm{Cu}$ absorption was reduced significantly in rats fed on the high-Sn diet (Fig. 5). The question which arises is how dietary $\mathrm{Sn}$ inhibits intestinal $\mathrm{Cu}$ absorption. Sn could compete with $\mathrm{Cu}$ for an undefined $\mathrm{Cu}$ carrier in the mucosa. $\mathrm{Sn}^{2+}$ in the digesta could reduce $\mathrm{Cu}^{2+}$ to $\mathrm{Cu}^{+}$which may lower $\mathrm{Cu}$ solubility and/or reduce $\mathrm{Cu}$ binding to physiological ligands, leading to impaired $\mathrm{Cu}$ absorption. So far experimental evidence is lacking for the possible mechanisms underlying the inhibitory effect of $\mathrm{Sn}$ on $\mathrm{Cu}$ absorption.

We conclude that high $\mathrm{Sn}$ intake reduces $\mathrm{Cu}$ status in rats by inhibiting $\mathrm{Cu}$ absorption which is followed by decreased excretion of $\mathrm{Cu}$ in bile. This hypothesis could be tested by infusing $\mathrm{Sn}$ intravenously which, if our hypothesis is correct, would not affect biliary $\mathrm{Cu}$ excretion.

Shiguang Yu was supported by The Netherlands Foundation for Nutrition and Health Research. Thanks are due to Gerrit van Tintelen for taking care of the rats.

\section{REFERENCES}

Cartwright, G. E. \& Wintrobe, M. M. (1964). Copper metabolism in normal subjects. American Journal of Clinical Nutrition 14, 224-232.

Dijkstra, M., Kuipers, F., Smit, E. P., De Vries, J. J., Havinga, R. \& Vonk, R. J. (1991). Biliary secretion of trace elements and minerals in the rat. Journal of Hepatology 13, 112-119.

Farrer, P. \& Mistilis, S. P. (1967). Absorption of exogenous and endogenous biliary copper in the rat. Nature 213, 291-292.

Fleck, C. \& Barth, A. (1990). Influence of xenobiotics on bile flow and bile composition in rats - methodological approach. Experimental Pathology 39, 175-185.

Greger, J. L. \& Johnson, M. A. (1981). Effect of dietary tin on zinc, copper and iron utilization by rats. Food and Cosmetics Toxicology 19, 163-166.

National Research Council (1978). Nutrient Requirements of Laboratory Animals, 3rd ed. Washington, DC: National Academy of Sciences.

Owen, C. A. Jr (1964). Absorption and excretion of $\mathrm{Cu}^{64}$-labelled copper by the rat. American Journal of Physiology 207, 1203-1206.

Pekelharing, H. L. M., Lemmens, A. G. \& Beynen, A. C. (1994). Iron, copper and zinc status in rats fed on diets containing various concentrations of tin. British Journal of Nutrition 71, 103-109.

SPSS Inc. (1988). SPSS/PC+V2.0 Base Manual. Chicago: SPSS.

Van den Berg, G. J. \& Beynen, A. C. (1992). Influence of ascorbic acid supplementation on copper metabolism in rats. British Journal of Nutrition 68, 701-715. 